Екатерина Руднева

\title{
РАЗГОВОР В ИНКЛЮЗИВНОЙ МАСТЕРСКОЙ
}

В статье анализируются фрагменты видеозаписи, сделанной в инклюзивной мастерской. Участники взаимодействия- инструктор, двое сотрудников с ментальными особенностями и два волонтера. Находясь за столом в керамической мастерской, они занимаются рабочими делами и ведут беседу о животных. Основной метод исследования- конверсационный анализ-дополнен этнографическими: включенным наблюдением (автор посещала организацию в качестве волонтера) и интервью. В статье обсуждаются обстоятельства сбоев (а также их отсутствия) во взаимодействии с участием людей с ментальными особенностями на рабочем месте. Выясняется, каким образом на достижение взаимопонимания влияют (а) особенности речи участников, (б) информация о том, что у кого-то есть ментальные особенности и (в)переключение между рабочей деятельностью и разговором на отвлеченную тему. В материале представлены случаи заикания, а также отсутствия ответа на вопрос и побуждение, которые нарушают или меняют ход взаимодействия (progressivity). Демонстрируется, что сбои в коммуникации-результат взаимодействия со всеми его обстоятельствами, а не нарушений отдельных участников. Одни и те же действия (заикание, отсутствие ответа или резкая смена темы) в одних случаях приводят к значительным нарушениям хода взаимодействия, а в других - нет, благодаря действиям собеседников. Нарушения или изменения хода взаимодействия обусловлены, прежде всего, тем, что участники по-разному переключаются между беседой и ручным трудом, не всегда реагируя на реплики друг друга (так, аутичный сотрудник не сразу реагирует на побуждение вернуться к работе, а инструктор не отвечает на несколько его вопросов, предлагающих для обсуждения новых животных). Нарушение последовательности, а именно отсутствие ответа на вопрос, демонстрируется со стороны участника без так называемых ментальных особенностей, и соответственно не связы-

Екатерина Алексеевна Руднева- к.филол.н., научный сотрудник, Институт лингвистических исследований РАН, Санкт-Петербург, Россия. Электронная почта: katja1985mt@yandex.ru 
вается с неполной прагматической компетенцией. При этом аналогичное нарушение последовательности со стороны человека с ментальными особенностями может быть объяснено собеседниками именно наличием этих особенностей. В целом, несмотря на некоторые сбои, в инклюзивной мастерской поддерживается связный разговор, тем самым достигается цель и реализуется идеология инклюзивного пространства.

Ключевые слова: конверсационный анализ, аутизм, инклюзивная мастерская, ментальные особенности, нарушения хода взаимодействия

DOI: 10.17323/727-0634-2021-19-4-565-584

Как следует из информации на сайте проекта «Простые вещи» (2021), инклюзивные мастерские- «это открытое пространство... где взрослые люди с особенностями развития психики и интеллекта работают и занимаются творчеством на равных с мастерами и волонтерами». Там встречаются сотрудники и волонтеры с мастерами (специалистами по керамике, кулинарии, шитью, столярному делу, графике), инструктирующими первых и вторых. «Инклюзивное пространство»- новое для России понятие, с которым многие не знакомы. Так, со слов одного из мастеров, среди людей, случайно зашедших с улицы, его «вообще никто не знает»: «Эксклюзивное? - Нет, инклюзивное!». Поэтому наготове более простое объяснение: «Вместе работаем сообща, обычные люди и люди с ментальными особенностями». Наименование люди с ментальными особенностями, которое используется в данной цитате (а также на официальном сайте организации), было выбрано и для настоящей статьи. Это выражение, являясь более эвфемистическим, в большинстве случаев содержательно соответствует варианту люди с ментальной инвалидностью.

Я посещала мастерские в феврале и марте 2020 г. в качестве волонтера. Волонтеры являются важной составляющей инклюзивного пространства: «Чтобы особые мастера чувствовали себя частью общества, работали и общались, рядом должны быть люди, которым интересно и важно приходить в мастерские и трудиться бок о бок с особыми людьми» (Простые вещи 2021). На установочной волонтерской встрече, куда приходят новички, рассказывают, что некоторые сотрудники имеют «особенности», некоторые«суперспособности», например, могут запоминать огромное количество дат. Здесь работают и получают регулярную зарплату люди, диагнозы которых (в частности, аутизм и умственная отсталость) специально не сообщаются ни волонтерам, ни мастерам, но при этом и не скрываются. Когда приходишь в мастерскую, то представляешься и знакомишься, не уточняя статус, как свой, так и остальных, а потом по возможности подключаешься к процессу. Приведу цитату из интервью с одним из мастеров:

У нас часто бывают такие случаи, когда вообще никто не может понять, кто есть кто. Пришел тихий волонтер, а говорят: 
- Это вот был из особых ребят?

- Нет.

- А это пришел, это точно волонтер был?

- Да нет, это не волонтер, он тут работает.

Основные задачи такого пространства-создание условий для совместного «осмысленного труда и общения» (Простые вещи 2021). Изучение того, как реализуются целевые и идеологические установки, как взаимодействуют участники с так называемыми особенностями и без них, необходимо для осмысления этой новой коммуникативной ситуации и возможностей, которые она открывает для людей с ментальной инвалидностью. Между тем социальное взаимодействие в инклюзивном пространстве еще не становилось исследовательским объектом. Основной вопрос настоящего исследования: чем обусловлены сбои (или их отсутствие) во взаимодействии с участием людей с ментальными особенностями на рабочем месте. В статье анализируются фрагменты разговора в керамической мастерской. В этом материале представлены случаи заикания, а также отсутствия ответа на вопрос и побуждение, которые нарушают или меняют ход взаимодействия (progressivity). Меня интересует, каким образом на достижение взаимопонимания и ход взаимодействия влияют (а) особенности речи участников, (б) информация о том, что у кого-то из участников ментальные особенности и (в) мультиактивность, под которой понимаются «различные способы пересечения и взаимоотношения двух или более видов деятельности в социальном взаимодействии» (Haddington et al 2014:3), конкретнее- переключение между рабочей активностью и разговором на отвлеченную тему.

Вследствие убеждения, что ответственность за сбои во взаимодействии лежит на участниках с коммуникативными нарушениями, именно их поведение оказывается в поле зрения большинства лингвистических и психологических работ. С другой стороны, конверсационный анализ (КА), выбранный здесь как основной метод, учитывает действия всех участников и позволяет показать, что взаимодействие- продукт их совместной деятельности. Еще одно убеждение, которое оспаривается в статье, это то, что люди с ментальными особенностями реже реагируют на действия собеседников правильным образом, в том числе не отвечая на задаваемые им вопросы.

\section{Организация и тема разговора}

Рассмотрим вкратце основные понятия КА, которые используются в статье. Реплики, или череды, будучи упорядоченными по отношению к друг другу, составляют последовательности (Schegloff 2007: 195). Для понимания того, какое действие совершается в реплике, принципиально важно ее место в последовательности (Sacks et al. 1974). Два череда образуют примыкающую пару, когда первая часть делает релевантными, 
ожидаемыми определенные варианты второй: например, вопрос и ответ, просьба и согласие или отказ. Если вторая часть пары не следует за первой, ее отсутствие является значимым и «таким же событием, как и наличие» (Schegloff 2007:20). В таком случае нарушается ожидаемая структура последовательности, а также ход взаимодействия (progressivity), под которым понимается переход от некоторого элемента к следующему без препятствий их смежности (Ibid: 15).

С точки зрения КА, связность разговора достигается, прежде всего, через организацию последовательности и «связывающие структуры», такие как референциальные и дейктические элементы, например, союзы и местоимения, через которые участники демонстрируют, что понимают реплики, на которые отвечают, и разговор в целом (Sacks 1995: 540). При этом важно различать последовательность как единицу организации и тему/тематическую связность, topi(ality) (Schegloff 2007: 113). Хотя темы чередов (о чем они) могут быть достаточно далеки друг от друга, эти череды связываются через то, какое положение в последовательности занимают (Ibid: 114).

Как отмечает Джек Сиднелл, «периодически темы в разговоре плавно перетекают одна в другую» (Sidnell 2010:228). Этот переход может осуществляться более или менее явно, резко или пошагово (Ibid: 233-244). В тех редких случаях, когда кто-то вводит новую тему «несвязным образом», он обычно предлагает обобщающий или оценочный комментарий на предыдущую тему (Drew, Holt 2005:3). Эммануэль Щеглов утверждает, что КА интересует, прежде всего, что разговор «делает» (talk-that-does), нежели то, о чем он (talk-about), и смещение фокуса исследовательского интереса на тему «может затуманить важные вопросы о том, что участники делали, разговаривая о том, о чем они разговаривали» (Schegloff 1990: 52). В ходе последующего мультимодального анализа учитываются, помимо речевых, действия телом: жесты, взгляды, движения головой, выражение лица, положение тела, передвижение в пространстве, манипуляции с предметами (Mondada 2016). Эти действия рассматриваются как шаги в последовательности, наряду с репликами.

\section{Изучение атипичного взаимодействия}

В рамках КА сформировалось направление по изучению так называемого «атипичного» взаимодействия, в частности когда у кого-то из участников (а)проблемы с языком, речью или слухом; (б)когнитивные нарушения, которые влияют на коммуникацию; (в) речь и язык относительно в норме, но состояние считается болезнью (Antaki, Wilkinson 2013: 533-534). Коммуникативные нарушения группируются по тому, какое влияние на социальное взаимодействие они оказывают, при том что схожее влияние могут оказывать различные состояния организма (Wilkinson et al. 2020). Как отмечают Чарльз Антаки и Рей Уилкинсон, в рамках КА нет систематических исследований, 
посвященных коммуникации людей с ментальной инвалидностью в зависимости от типа или серьезности диагноза: исследователи «игнорируют широкие официальные диагнозы», так как подобные ярлыки «могут затуманить их видение того, что человек может на самом деле делать» во взаимодействии (Antaki, Wilkinson 2013: 541-542).

Важно, напротив, изучить функции тех действий, которые рассматривались лишь как отклонения. Такой подход к КА позволяет достичь интересных результатов в интерпретации интеракционных функций эхолалии (автоматических повторений) и формульных выражений, характерных для людей с аутизмом (Dobbinson et al. 2003; Local, Wootton 1995). Еще одним важным аспектом таких исследований стало смещение исследовательского интереса с речи исключительно человека с диагнозом (пациента или испытуемого) на взаимодействие всех участников. И наконец, во многих современных работах КА сочетается с этнографическим методом-наблюдением- позволяющим лучше понять контекст (напр., Ochs et al. 2004).

Подход, при котором изучается взаимодействие как совместный продукт всех собеседников, а не только речь участника с диагнозом, позволяет прийти к революционным выводам по сравнению с теми, которые получаются в ходе экспериментов. Так, КА коммуникации с участием людей с умственной отсталостью в институциальном контексте позволил показать, что «значительная часть внешней атипичности этих взаимодействий во многом является следствием практик участников без инвалидности» (Walton et al. 2020: 124). Дуглас Мейнард и Джейсон Туровец убедительно продемонстрировали, как сбои в коммуникации, возникшие в результате действий всех собеседников, могут использоваться как доказательства проблем аутичного участника, стигматизируя его и способствуя преобладанию подхода к инвалидности, в центре которого находятся дефекты (Maynard, Turowetz 2020: 58). Это принципиальное отличие КА согласуется с моделью «обоюдной эмпатии» (double-empathy), сформулированной Дэмианом Милтоном, аутичным исследователем, согласно которой непонимание - это не результат нарушений человека с аутизмом, а общая интеракционная проблема (Milton 2012). Такой подход отличается от традиционного принятого в психологии, при котором особенности коммуникации аутистов описываются в терминах нарушений (Медведовская, Лебедева 2011; Baron-Cohen et al. 1985).

\section{Метод исследования}

Материалом исследования стали видеозаписи, сделанные в инклюзивной мастерской, которую я посещала в качестве волонтера в течение двух месяцев. Запись на видеокамеру телефона велась во время каждого посещения, за исключением дня знакомства. На видеозапись получено разрешение от руководства организации. Кроме того, при поступлении 
на работу сотрудники подписывают разрешение на фото- и видеосъемку. Я каждый раз спрашивала разрешение включать камеру у всех присутствующих, а также присутствовала на двух волонтерских встречах, на которых запись не делала.

Основным методом стал КА, который дополнился этнографическими-включенным наблюдением, ведением полевого дневника и интервью с некоторыми мастерами. Знание контекста становится преимуществом для исследования: взаимопонимание достигается не только за счет понимания слов, но и обстоятельств коммуникации (Goodwin, Duranti 1992). Включенное наблюдение позволило, во-первых, лучше понять происходящее, во-вторых, в меньшей степени влиять на взаимодействие (то есть вклад во взаимодействие с моей стороны внесен в роли участника-волонтера). Полевой дневник, фиксирующий восприятие происходящего исследователем-участником, позволил обогатить материал, добавляя впечатления одного из коммуникантов.

Ниже представлен анализ фрагментов разговора, записанного в керамической мастерской. Участники данного взаимодействия-инструктор керамической мастерской Мария, двое сотрудников с ментальными особенностями Василий и Павел (у которого диагностирован аутизм), Екатерина и Светлана. Диалог продолжается в течение 17 минут, перемежаясь с фразами, касающимися рабочей деятельности. Во время разговора участники лепят посуду из глины и «обмывают» изделия, т. е. обтирают шероховатости влажной тряпкой, занимаются уборкой.

\title{
Анализ материала
}

\section{Фрагмент $1^{1}$}

\author{
001 B: Маш тебе нужен енот? \\ 002 М: ((обходит В, наклоняется к В)) \\ 003 М: что? \\ 004 В: енот (.) нужен? \\ 005 М: ен[от?] ((улыбаясь)) \\ 006 В: [да ] \\ 007 M: живой? ((улыбаясь)) \\ 008 В: да
}

1 См. символы транскрипции: https://jsps.hse.ru/article/view/13612/13342 
$009 \quad(1.0)$

010 М: я боюсь что он не сможет у меня жить.

011 [енот ] очень активный.

012 В: [почему?]

$013 \quad(0.8)$

014 B: почему не сможет?

015 M: я видела на ютюбе видео (0.5) про енота вилли (0.4) и

016 там енот вилли он (0.4) живёт в доме и он все крушит.

017 он крушил кухню, там проделал (0.2) в стене дырку (0.2)

018 оттуда вылезал, залезал туда, (0.6) и в общем я боюсь

019 что у меня дома он все сокрушит

$020 \quad($.

021 С: [да: у меня ] у знако[мого ]

022 П: [((открыл рот))] [знаешь]

023 С: енот живет (0.6) и он

$024 \quad(0.5)$

025 П: знае[те о чём я] думал?

026 C: [залез ]

027 П: ((смотрит на С))

028 С: угм?

029 П: я зря прикрепил таблички о том что вход разреш

$030 \quad(0.4)$ режисён

031 C: енотам?

032 П: вход (.) рыже (.) разрешен ээ (0.8) с животнэ с живОтным,

033 (2.0) птицами и в том чи[сле: ],

034 M: [поче]му?

035 M: ((переводит взгляд с рук П на лицо П))

036 очень красивые таблички

037 ((смотрит на П))

038 С: да: [очень кра- ]

039 П: $\quad$ [(???)в жэке] грозил мне снять всё это. 
$040 \quad(0.8)$

041 M: ой. (0.5) это же не он решает снимать это или не снимать

042 (0.3) не в его компетенции (0.6) решать такие вещи (.)

043 всем остальным нравится.

$044 \quad(1.8)$

045 П: наверно из-за того что он не любит э: (0.5) ле- он не любит

046 этих (0.7) лему: ров обезьян ((очищая карточку))

$047 \quad(0.7)$

048 М: да: ((поднимая брови))

049 П: ленивцев броненосцев и муравьедов

$050 \quad(1.5)$

051 М: ну не зна: ю

$052 \quad(0.4)$

053 П: еще енотов барсуков

$054 \quad(1.0)$

055 М: не любит?

056 П: ((качает головой))

057 М: ты его спросил? [не любит ] ли он их

058 П: $\quad$ [((мотает головой))]

059 М: надо спросить.

$060 \quad(1.2)$

061 П: он любит собак.

Василий вводит новую тему про енота (1), которая до этого никак не затрагивалась. При этом он улыбается и смотрит на Марию, и она также начинает улыбаться после ответа на свой первый переспрос (3), демонстрируя понимание шуточной составляющей. Ее реакция состоит из серии переспросов $(3,5,7)$, следующих после небольшой паузы: так берется отсрочка для обдумывания. Эти переспросы, а также паузы $(9,13)$ свидетельствуют о том, что такой ввод темы является несколько резким и неожиданными для Марии. Она дает ответ не сразу (10), а затем продолжает беседу, рассказывая про видео с енотом Вилли (15-19). Вторую историю начинает рассказывать Светлана- про питомца, жившего у знакомого $(21,23,26)$. Обе истории объединяет то, что они забавные: это показывает одинаковую 
интерпретацию разговора со стороны двух участниц. Пока Василий и Мария беседуют, Павел двигает губами и слегка улыбается.

Пытаясь вступить в диалог, Павел сначала открывает рот; затем происходят наложения его фразы с репликой Светланы (21-22, 25-26). После этого она завершает свой черед, обрывает историю, тем самым предоставляя Павлу возможность задать вопрос для захвата внимания (25). Первая реакция Светланы- переспрос, попытка связать фразу про таблички с предшествующим разговором (31). Эта реплика могла бы быть проинтерпретирована как шутка, но за ней не следует соответствующая реакция (например, смех). Речь идет о табличках, которые Павел придумал, сделал и повесил у входа в мастерские,- и собеседницы поддерживают разговор на эту тему.

Несмотря на заикание в реплике Павла (29-30, 32), собеседники некоторое время слушают, не пытаясь взять черед, за исключением минимального утоняющего переспроса (30), предлагающего связать реплику про таблички с темой енотов. Однако чуть позже вопрос Марии («почему?», 34) обрывает фразу Павла на «в том числе» (33), о чем свидетельствует интонация перечисления. При этом Мария поддерживает Павла оценочным комментарием («очень красивыле таблички», 36); Светлана также начинает подобную реплику (38). Мария реагирует на эмоциональную составляющую, на то, что Павел именно «зря прикрепил таблички»: она успокаивает, а затем объясняет, в чем не прав представитель ЖЭКа (41-43). Через такую реакцию участников поддерживается формат рассказа. Нужно отметить, что случай, который вспомнила Светлана, остается интересным собеседникам, и Василий вернется к нему через несколько минут.

Позже выясняется, как с предыдущим разговором тематически связана реплика про таблички: на них говорится о животных (45-53). Приводя в пример животных, которых не любит этот самый представитель ЖЭКа, Павел перечисляет и енотов, наряду с лемурами, обезьянами, ленивцами, муравьедами и барсуками $(46,49,53)$. А если вернуться к реплике про таблички, то становится ясно, что это перечисление, вероятно, могло оказаться раньше, как продолжение фразы про то, что вход разрешен «с животнылми, птицами и в том числе» (32-33), если бы Павел получил возможность закончить фразу. Далее Павел отвечает на вопросы Марии мотанием головы (56), оставляет без ответа реплику «надо спросить» (59) и завершает свою историю, сообщая, что представитель ЖЭКа «любит собак» (61). Мария внимательно слушает, реагирует минимальными ответными репликами. Таким образом, в данном фрагменте демонстрируется работа Светланы и Марии по поддержанию связного разговора на темы, введенные Василием и Павлом.

\section{Фрагмент 2}

01 M: да: лучше всё-таки рыбок дома держать, это удобней

02 П: а муравьеда? 
03

04 M: хотя я бы не стала держать рыбок,

05 я бы забывала их кормить. это было бы жестоко

$06 \quad$ (.)

07 П: а кош[ек? ]

08 M: [и ВО]ду менять тоже забывала бы ((улыбаясь))

$09 \quad(0.3)$

10 E: муравьеда сюда?

$11 \quad(0.2)$

12 П: угм ((смотря на Е))

13 B: ((смеется))

14 M: ну в нашем климате он бы не выжил наверно

15 B: не не почему есть (которые) держат дома (.) муравьедов

16 (.)

17 M: да? (.) ну это наверно очень особые условия нужно

$18 \quad(0.7)$

19 П: ну [а-] ((остался с открытым ртом, смотрит в сторону М и В))

20 В: или э[ти]

21 M: $\quad$ [от]лично ((беря в руки изделие))

$22 \quad(0.4)$

23 В: или типа ли- (0.4) кто там

24 П: ленивца

25 В: типа льльлисы только

26 ма[ленькая есть ещё]

27

M: [а ленивцу ] тоже нужна жара

28

Диалог протекает таким образом, что если взять небольшой фрагмент 1-7, то связь соседних реплик, кажется, отсутствует; создается впечатление, что каждый разговаривает на свою тему: Мария рассуждает об аквариуме на рабочем месте, а Павел задает вопросы про муравьеда (2) и кошек (7), которые сначала остаются без ответа. После того, как Екатерина переспросом реагирует на вопрос про муравьеда (10), Светлана и Василий также поддерживают этот тематический поворот (14-15). Далее Павел снова пытается взять черед, но ему не удается это сразу (19). Однако по началу фразы «ну $a »$, можно предположить, что продолжением должно было стать название следующего животного. Когда Павел открывает рот, 
остальные участники на него не смотрят. Здесь происходит тройное наложение реплик (19-21). Таким образом, его участие обусловлено особенностями речи, тем, что он медленнее начинает фразу, а кроме того, мультиактивностью и отсутствием постоянного зрительного контакта. Добавлю, что для Павла вступить в диалог- задача не тривиальная; анализ других записей с его участием позволяет проследить, как решается эта проблема. Так, прежде чем начать говорить, он иногда долго смотрит на собеседника, ожидая более длительной паузы.

После небольшого заикания в реплике Василия (23), Павел оперативно предлагает свой вариант завершения названия животного, начинающегося на «ли»- «ленивцуа» (24). Хотя выясняется, что Василий имел в виду лису (25), Мария делится известной информацией о ленивце (27-28). Затем Павел совершает несколько попыток вернуться в беседе к интересующим его животным, и наконец, ему удается еще раз это сделать:

\section{Фрагмент 3}

01 M: так давай, делаем еще

02 ((смотрит на настенные часы))

03 делаем еще тарелку

04 П: ((смотрит на М)

05 М: [еще успеваем ]

06 П: [((смотрит на часы))]

07 ((смотрит на глину, шевелит губами))

08 М: [так паш ]

09 П: [ну и что]тоже

10 М: счас при[думаем]

11 П: [трудно]

12 ли держать игуану или чере- черепаху? ((трогая глину))

$13(0.3)$

14 M: та: к эти все готовы, ((проверяя формы))

15 E: ну черепаху мне кажется не тру: дно

$16 \quad(0.2)$

17 может

18 [ей не очень нравится ]

19 M: [у меня есть предложение],

20 давай сделаем уборку, ((показывая руками))

21 и отомнем еще одну тарелочку, ты отомнешь

22 ((смотрит на П)) 
23 потому что время еще есть а формы уже все залиты,

24 П: ((собирает крошки))

25 M: все почищены и все сделано

26 В: черепахи они очень медленные,

27 их проще сам- очень легко содержать

28 П: ((вытирает стол))

29 М: ко[го? ]((смотря на В))

30 B: [чере]пах ((поворачиваясь к M))

31 M: ну да, черепахам ничего не будет

32 ((начинает убирать глиняную пыль))

33 В: просто [я видел ]

34 П: [еще кто-то] сказал,

35 B: как содержать черепах, просто фигня

36 П: и еще кто-то сказал что мура-вьеду

37 B: нужна жара и листья

38 ((усмехается))

39 a, а на самом деле муравьеды питаются

40 термитами и муравьями

41 M: нет я говорила про ленивцев, им нужны листья

42 B: ну еще белочек бывает содержат, ((смотря на M))

43 но это очень редко

$44 \quad(0.2)$

45 П: а броненосца тоже нельзя держать дома?

46 M: я думаю что такие животные они страдают если их

47 держать дома,

48 потому что они привыкли к дикой природе

Павел реагирует на предложение Марии сделать еще тарелку следующим образом: смотрит на собеседницу (4), а затем на часы (6), но не переходит к работе над изделием. На отсутствие переключения к рабочей деятельности Мария реагирует одним из возможных способов- стоит и ждет. Павел продолжает интересующую его тему, задавая вопрос про игуану и черепаху (11-12). Мария не отвечает на его вопрос, продолжая разговор о работе (14). Таким образом, Мария и Павел произносят свои реплики по очереди, но не отвечают друг другу. Здесь нарушается последовательность, т.к. за первой частью примыкающей пары не следует вторая: за вопросом ожидается ответ, а за побуждением к действию- ответная реакция или само действие, а в случае 
его отсутствия- объяснение причины. Ситуацию можно было бы посчитать зеркальной, если не принимать во внимание то, что Мария говорит о работе. При этом Павел все же реагирует на инструкции, но в своем темпе, концентрируюсь на разговоре, который, очевидно, занимает его больше лепки.

На вопрос Павла отвечает Екатерина (15-18) и потом Василий (26-27), а Мария пытается снова привлечь внимание к тарелкам, оформляя побуждение как «предложение» с объяснением (19-25). На ее инструкции Павел опять реагирует не словами, а движениями, но уже касающимися уборки: собирает крошки (24) и вытирает стол (28). Отметим, что в имеющихся записях он никогда не дает вербальный ответ на инструкцию.

Сначала Мария не принимает участие в разговоре о черепахах, но когда к новой теме присоединяются другие собеседники, она тоже делает это, задавая уточняющий вопрос (29). После того, как Василий поворачивается к ней, Мария дает минимальный необходимый ответ (31), занимаясь при этом основным, с ее точки зрения, делом- уборкой со стола. В отличие от Павла, Василий адресует свои реплики конкретным собеседникам, поворачиваясь к ним, особенно когда их внимание распределено между несколькими действиями. Обосновывая свою точку зрения, Василий приводит аргумент «я видел» (33-35).

В реплике 36-37 Павел отсылает к фразе, которую Мария произнесла несколько минут назад (фрагмент 2, 27-28), причем он это делает, не обращаясь к ней прямо, а через косвенную речь: «и еще кто-то сказал» (36). В этой реплике используется формат продолжения темы «И ещзе...», который создает ожидание того, что информация релевантна. Павел ставит под сомнение утверждение Марии, что вызывает усмешку Василия (38).

Интересно взглянуть на циркуляцию тем, происходящую в диалоге в приведенном фрагменте и далее. Так, помимо рабочих вопросов, Мария вновь и вновь напоминает про защиту животных, объясняя, почему неправильно содержать диких зверей дома (46-48). Павел продолжает предлагать животных для обсуждения: минипигов, обезьян, сов, петуха, ежика, доходя до ехидны. Все участники возвращаются к своим темам, то же делает и Павел. Если попробовать встать на его точку зрения, то иногда собеседники уделяют внимание тому, что ему кажется нерелевантным в данный момент (например, когда он задает вопрос про животных, Мария отвечает предложением сделать еще тарелку). Отметим, что Павел может принимать некоторое участие в разговоре и одновременно выполнять однообразные действия, например, чистить карточку, которой он разглаживал глину, или убирать поверхность. При этом его переключение с одного вида деятельности на другой происходит скорее поэтапно и не сразу, по сравнению с другими участниками (см.: Руднева 2021).

Одна из причин, почему в одних случаях за фразами Павла следует реакция, приветствующая продолжение диалога, а в других его реплики игнорируются, это ориентация мастера на результат ручного труда. Мария 
в большей степени заботится о результате и стимулирует переход к рабочей деятельности. Шуточный диалог на рабочем месте обычно продолжается недолго: он выполняет функции поддержания отношений, но не должен отвлекать от занятия, которое считается основным. Совсем иначе к разговору относятся Павел и Василий: им он гораздо более интересен, чем изготовление глиняной продукции. Несколько раз попытки Марии вернуть взаимодействие в рабочее русло полностью игнорируются другими участниками. Интересно, что настойчивые попытки возобновить рабочую активность начинаются по прошествии четырех минут с вопроса Василия о енотах. Таким образом, по-видимому, у мастера есть ощущение того, сколько может продолжаться разговор на отвлеченную тему и пауза в основной работе.

\section{Фрагмент 4}

01 П: <а ехидну $>$ ?

$02 \quad(0.8)$

03 M: ехидну? боже я про ехидну ничего не знаю. (0.2)

04 но наверное ей совсем дома не понравится

05 П: это (0.1) яйцекладущие

$06 \quad(0.3)$

07 М: ммм ((улыбается))

08 E: она же хищная?

$09 \quad(1.0)$

10 П: не ясно

11 E: $\mathrm{M}$

12 П: никто точно даже не знает хищники это или вегетарианец

13 M: ((смеется))

14 (1.0) ((смотрит на П))

15 M: паш, давай быстренько убираемся,

16 еще тарелку успеем сделать

$17 \quad(0.8)$

18 M: а то мы че-то совсем с тобой увлеклись разговорами,

19 В: а что такого здесь?

$20 \quad(2.8)$

21 M: ((наклоняется к изделию В))

22 M: что там, пузырики? смотри пузырики, вот тут. тут. тут. 
Павел задает вопрос про ехидну (1), а Мария и Екатерина проявляют ответный интерес $(3-4,8)$. Высказывания Павла о том, что ехидна- яйцекладущая (5) и что она «вегетарианеи», вызывают улыбку (7) и смех (12). Далее Мария совершает очередную попытку переключить Павла на рабочую деятельность $(15,16)$ и объясняет необходимость сделать это тем, что, с ее точки зрения они «совсем... увлеклись разговорами» (18). На это возражает Василий (19). После паузы Мария наклоняется к его изделию, показывая, как удалять «пузырики».

Как видно из анализа, значительно отличается вклад во взаимодействие со стороны двух сотрудников с ментальными особенностями. Для Павла характерен возврат к выбранной теме животных. При этом его вопросы повторяют одну и ту же структуру в полной и сокращенной форме: (а) А еще трудно содержать дома попугая/канареек/тукана? (б)А ехидну/ кошек/петуха/муравьеда? Павел совсем не говорит о работе, а на реплики, касающиеся ее, реагирует только невербальными действиями. Василий проявляет себя как участник, в полной мере владеющий прагматикой: он шутит и мгновенно реагирует на шутки, хорошо чувствует смену темы и в большинстве случаев поддерживает собеседников, адресует свои высказывания конкретным людям, в том числе поворачиваясь к ним.

\section{Заключение}

В целом, несмотря на некоторые сбои, в мастерской поддерживается связный разговор с участием людей с ментальными особенностями-тем самым достигается цель и реализуется идеология инклюзивного пространства. Изменения и нарушения хода взаимодействия обусловлены, прежде всего, тем, что собеседники переключаются между рабочей активностью и беседой на отвлеченную тему, не всегда реагируя на реплики друг друга. Вторая причина-различия в приоритетах между этими курсами деятельности и в трактовках ситуации: разговор о животных для кого-то оказывается сопровождающим работу, местами шуточным, а для кого-то- основным делом, важнее изготовления глиняной посуды. Через четыре минуты после начала беседы о животных, мастер, в большей степени ориентируясь на результат труда, совершает несколько попыток вернуть аутичного сотрудника к лепке.

В анализируемом взаимодействии отмечается работа мастера и волонтеров, направленная на поддержание беседы с сотрудниками с ментальными особенностями. Менее ожидаемая в конкретном контексте реплика может быть встроена в диалог ответными действиями: если на неуместную, на первый взгляд, фразу участники отвечают привычным образом, она перестает являться таковой. При этом в одних случаях собеседники реагируют на реплики аутичного собеседника так, чтобы встроить их в общий диалог, в других случаях его реплики остаются без внимания, в том числе и некоторые вопросы, предлагающие новых животных для обсуждения. Отсутствие второй 
части примыкающей пары наблюдается с обеих сторон: аутичный сотрудник не отвечает сразу на побуждение к действию, а мастер не отвечает на несколько его вопросов о животных. Аналогично, в одних случаях заикания двух участников незначительно влияют на ход взаимодействия-когда собеседники ждут и дают возможность завершить фразу. В других же случаях заикание и замедленное начало фразы приводят к тому, что аутичному сотруднику не удается взять черед или завершить реплику.

Таким образом, сбои в коммуникации-результат взаимодействия со всеми его обстоятельствами, а не индивидуальных особенностей отдельных участников. Одни и те же действия (заикание, отсутствие парной реплики и резкая смена темы) в одних случаях приводят к более ощутимым нарушениям хода взаимодействия, а в других-нет, благодаря реакции собеседников. Участники коммуникации интерпретируют сбои во взаимодействии с учетом знаний о собеседнике. Между тем нарушение последовательности, в частности отсутствие ответа на вопрос, может быть связано с различными обстоятельствами, прежде всего, с мультизадачностью. Такое поведение демонстрируется в рассмотренных примерах со стороны участника без так называемых ментальных особенностей, и соответственно не связывается с отсутствием понимания или неполной прагматической компетенцией. При этом нарушение последовательности со стороны человека с ментальными особенностями может быть объяснено собеседниками именно наличием этих особенностей.

\section{Выражение признательности}

Автор выражает признательность Андрею Корбуту, Александре Курленковой, Александру Широкову, Марии Ерофеевой, Дмитрию Колядову, а также другим участникам дата-сессий.

Редакция благодарит программу «Университетское партнерство» за поддержку и возможность опубликовать данную статью.

\section{Список источников}

Медведовская Т.А., Лебедева Е.И. (2011) Как мы понимаем поведение других людей, или «модель психического». Аутизм и нарушения развития, 2 (33): 22-34.

Простые вещи (2021) Офиизиальный сайт. Доступно по ссылке: https://prostieveschi. ru/about-us (дата обращения: 1 сентября 2021).

Руднева Е.А. (2021) Переключение к рабочей деятельности в инклюзивной мастерской: мультимодальный анализ взаимодействия. Компьютерная лингвистика и интеллектуальные технологии: по материалам международной конференции «Диалог», (20): 587-596. 
Antaki C., Wilkinson R. (2013) Conversation Analysis and the Study of Atypical Populations. In: J. Sidnell, T. Stivers (eds.) Handbook of Conversation Analysis. Oxford: Blackwell-Wiley: 533-550.

Baron-Cohen A., Leslie A. M., Frith U. (1985) Does the Autistic Child Have a 'Theory of Mind?' Cognition, (21):37-46.

Dobbinson S., Perkins M.R, Boucher J. (2003) The Interactional Significance of Formulas in Autistic Language. Clinical Linguistics \& Phonetics, 17 (4-5): 299-307.

Drew P., Holt E. (2005) Figurative Pivots: The Use of Figurative Expressions in Pivotal Topic Transitions. Research on Language and Social Interaction, 38 (1):35-61.

Goodwin Ch., Duranti A. (1992) Rethinking Context: An Introduction. In: A. Duranti, Ch. Goodwin (eds.) Rethinking Context: Language as an Interactive Phenomenon. Cambridge: Cambridge University Press, 1992: 1-34.

Haddington P., Keisanen T., Mondada L., Nevile M. (2014) Towards Multiactivity as a Social and Interactional Phenomenon. In: P. Haddington, T. Keisanen, L. Mondada, M. Nevile (eds.) Multiactivity in Social Interaction: Beyond Multitasking. Amsterdam: John Benjamins Publishing Company:3-32.

Local J., Wootton A. J. (1995) Interactional and Phonetic Aspects of Immediate Echolalia in Autism: A Case Study. Clinical Linguistics and Phonetics, (9): 155-194.

Maynard D. W., Turowetz J. (2020) Sequence and Consequence: Transposing Responsive Actions into Provocations in Forensic and Clinical Encounters Involving Youths with Autism. In: R. Wilkinson, J. P. Rae, G. Rasmussen (eds.) Atypical Interaction: The Impact of Communicative Impairments within Everyday Talk. Cham: Palgrave Macmillan:39-64.

Milton D. (2012) On the Ontological Status of Autism: The Double Empathy Problem. Disability and Society, 27 (6): 883-887.

Mondada L. (2016) Multimodal Resources and the Organization of Social Interaction. In: A. Rocci, L. De Saussure (eds.) Handbooks of Communication Science. Berlin: De Gruyter: 329-350.

Ochs E., Kremer-Sadlik T., Sirota K. G., Solomon O. (2004) Autism and the Social World: An Anthropological Perspective. Discourse Studies, (6): 147-183.

Sacks H. (1995) Lectures on Conversation, Vol. 1. Oxford: Basil Blackwell.

Sacks H., Schegloff E., Jefferson G. (1974) A Simplest Systematics for the Organization of Turn-Taking for Conversation. Language, 50 (4): 696-735.

Schegloff E. A. (1990) On the Organization of Sequences as a Source of 'Coherence' in Talkin-interaction. In: B. Dorval (ed.) Conversational Organization and Its Development. Norwood, NJ: Ablex: 51-77. 
Schegloff E. A. (2007) Sequence Organization in Interaction: A Primer in Conversation Analysis. Cambridge: Cambridge University Press.

Sidnell J. (2010) Conversation Analysis: An Introduction. West Sussex: Wiley-Blackwell.

Walton C., Antaki Ch., Finlay W.M.L. (2020) Difficulties Facing People with Intellectual Disability in Conversation: Initiation, Co-ordination, and the Problem of Asymmetric Competence. In: R. Wilkinson, J.P. Rae, G. Rasmussen (eds.) Atypical Interaction: The Impact of Communicative Impairments within Everyday Talk. Cham: Palgrave Macmillan:93-128.

Wilkinson R., Rae J.P., Rasmussen G. (eds.) (2020) Atypical Interaction: The Impact of Communicative Impairments within Everyday Talk. Cham: Palgrave Macmillan. 


\section{Ekaterina Rudneva}

\section{TALK IN AN INCLUSIVITY WORKSHOP}

The article analyses extracts of a video recorded in a Russian inclusivity workshop. The participants of the interaction are an instructor, two employees with mental disabilities, and two volunteers. Being involved in a ceramic workshop, they are talking about animals. The main research method is conversation analysis, which is backed up with ethnographic methods, mainly participant observation (the author attended the workplace as a volunteer) and interviews. The article discusses disruptions and delays of progressivity in workplace interaction involving neurodiverse people, as well as how counderstanding is influenced by (a) speech peculiarities, (b) awareness about one's disabilities label, (c) switching between two courses of action, namely work and talk. The data contain cases of stuttering, missing replies to questions or directives, and abrupt topic shifts. Conversation analysis demonstrates that progressivity disruptions are the result of interaction with all its circumstances, rather than of individual impairments. The same actions (in particular, stuttering, missing second pairs or abrupt topic shifts) can either lead to significant progressivity changes or not, depending on work done by all interlocutors. Progressivity disruptions are mainly caused by switching between the conversation about animals and work, leading interlocutors to fail to provide second pair parts (an autistic person does not promptly react to directives concerning work, while the instructor does not reply to his questions introducing new animals to discuss). Disruption of a sequence - a missing response to a question-is demonstrated by a participant without mental disabilities, and, accordingly, is not associated with incomplete pragmatic competence. On the contrary, similar violation of sequence organization by a person labeled with mental disabilities could be attributed to his label by interlocutors. In general, despite some disruptions, coherent conversation is maintained in the inclusivity workshop, fulfilling its goals and catering for its ideology.

Keywords: conversation analysis, inclusivity workshop, mental disabilities, progressivity disruptions, autism

DOI: 10.17323/727-0634-2021-19-4-565-584

\section{References}

Antaki C., Wilkinson R. (2013) Conversation Analysis and the Study of Atypical Populations. In: J. Sidnell, T. Stivers (eds.) Handbook of Conversation Analysis. Oxford: Blackwell-Wiley: 533-550.

Baron-Cohen A., Leslie A. M., Frith U. (1985) Does the Autistic Child Have a 'Theory of Mind?' Cognition, (21):37-46.

Ekaterina Rudneva- Cand. Sci. (Philol.), Researcher, Institute for Linguistic Studies, Russian Academy of Sciences, St. Petersburg, Russian Federation. Email: katja1985mt@yandex.ru 
Dobbinson S., Perkins M.R, Boucher J. (2003) The Interactional Significance of Formulas in Autistic Language. Clinical Linguistics \& Phonetics, 17 (4-5): 299-307.

Drew P., Holt E. (2005) Figurative Pivots: The Use of Figurative Expressions in Pivotal Topic Transitions. Research on Language and Social Interaction, 38 (1):35-61.

Goodwin Ch., Duranti A. (1992) Rethinking Context: An Introduction. In: A. Duranti, Ch. Goodwin (eds.) Rethinking Context: Language as an Interactive Phenomenon. Cambridge: Cambridge University Press, 1992: 1-34.

Haddington P., Keisanen T., Mondada L., Nevile M. (2014) Towards Multiactivity as a Social and Interactional Phenomenon. In: P. Haddington, T. Keisanen, L. Mondada, M. Nevile (eds.) Multiactivity in Social Interaction: Beyond Multitasking. Amsterdam: John Benjamins Publishing Company:3-32.

Local J., Wootton A.J. (1995) Interactional and Phonetic Aspects of Immediate Echolalia in Autism: A Case Study. Clinical Linguistics and Phonetics, (9): 155-194.

Maynard D. W., Turowetz J. (2020) Sequence and Consequence: Transposing Responsive Actions into Provocations in Forensic and Clinical Encounters Involving Youths with Autism. In: R. Wilkinson, J. P. Rae, G. Rasmussen (eds.) Atypical Interaction: The Impact of Communicative Impairments within Everyday Talk. Cham: Palgrave Macmillan:39-64.

Medvedovskaja T. A., Lebedeva E. I. (2011) Kak my ponimaem povedenie drugih ljudej, ili 'model' psihicheskogo' [How we Understand Behaviour of Other People, or 'Theory of Mind']. Autizm i narushenija razvitija [Autism and Developmental Disorders], 2 (33):22-34.

Milton D. (2012) On the Ontological Status of Autism: The Double Empathy Problem. Disability and Society, 27 (6): 883-887.

Mondada L. (2016) Multimodal Resources and the Organization of Social Interaction. In: A. Rocci, L. De Saussure (eds.) Handbooks of Communication Science. Berlin: De Gruyter:329-350.

Ochs E., Kremer-Sadlik T., Sirota K. G., Solomon O. (2004) Autism and the Social World: An Anthropological Perspective. Discourse Studies, (6): 147-183.

Rudneva E. A. (2021) Pereklyuchenie k rabochey deyatel'nosti v inklyuzivnoy masterskoy: mul'timodal'nyy analiz vzaimodeystviya [Switching to Work in an Inclusivity Workshop: Multimodal Analysis of Interaction]. Papers from the Annual International Conference 'Dialogue,' (20): 587-596.

Sacks H. (1995) Lectures on Conversation, Vol. 1. Oxford: Basil Blackwell.

Sacks H., Schegloff E., Jefferson G. (1974) A Simplest Systematics for the Organization of TurnTaking for Conversation. Language, 50 (4): 696-735.

Schegloff E. A. (1990) On the Organization of Sequences as a Source of 'Coherence' in Talk-ininteraction. In: B. Dorval (ed.) Conversational Organization and Its Development. Norwood, NJ: Ablex: 51-77.

Schegloff E. A. (2007) Sequence Organization in Interaction: A Primer in Conversation Analysis. Cambridge: Cambridge University Press.

Sidnell J. (2010) Conversation Analysis: An Introduction. West Sussex, UK: Wiley-Blackwell.

Simple Things (2021) Official Website. Available at: https://prostieveschi.ru/about-us (accessed 2 September 2021).

Walton C., Antaki Ch., Finlay W.M.L. (2020) Difficulties Facing People with Intellectual Disability in Conversation: Initiation, Co-ordination, and the Problem of Asymmetric Competence. In: R. Wilkinson, J.P. Rae, G. Rasmussen (eds.) Atypical Interaction: The Impact of Communicative Impairments within Everyday Talk. Cham: Palgrave Macmillan:93-128.

Wilkinson R., Rae J.P., Rasmussen G. (eds.) (2020) Atypical Interaction: The Impact of Communicative Impairments within Everyday Talk. Cham: Palgrave Macmillan. 